\title{
Comportamento informacional: proposição de artefato para reflexão de interdependências entre dimensões de qualidade da informação
}

José Osvaldo De Sordi

Docente pesquisador Programa de Mestrado em Administração das Faculdades Metropolitanas Unidas (FMU).Doutor em Administração pela Fundação Getulio Vargas (FGV-EAESP)

Thiago Carandina

Docente do Bacharelado em Administração da Faculdade Campo Limpo Paulista (FACCAMP). Mestre em Administração pela Faculdade Campo Limpo Paulista (FACCAMP)

http://dx.doi.org/10.1590/1981-5344/2389

Seguindo os preceitos da abordagem Design Science Research, desenvolveu-se e testou-se o artefato "Engrenagem para Análise da qualidade da informação". $O$ artefato objetiva sensibilizar os trabalhadores da informação quanto à importância da reflexão das interdependências entre as dimensões de qualidade da informação antes de se realizar qualquer ação junto ao recurso informação. Testes realizados junto a 33 funcionários, de seis micro e pequenas empresas intensivas em conhecimento, evidenciaram a efetividade do artefato. Após treinamento e uso do mesmo, observou-se alteração de comportamento informacional dos funcionários, especialmente com relação às dimensões raridade, disponibilidade, originalidade e precisão da informação.

Palavras-chave: Comportamento informacional; Mudança de comportamento; Trabalhador da informação; Qualidade da informação. 


\section{Informational behavior: proposition of artifact for interdependencies analysis between dimensions of information quality}

Following the precepts of the Design Science Research, this research developed and tested the device "Gear for analysis of information quality." This artifact objective sensitize information workers about the importance of reflection of interdependencies between dimensions of information quality prior to performing any action at the resource information. Tests conducted with 33 employees of six micro and small knowledge-intensive companies showed the effectiveness of the artifact. After training and use of the artifact, there was a change of information behavior of information workers, in particular with respect to dimensions: rarity, availability, originality and accuracy of the information.

Keywords: Informational behavior; Behavior change; Information worker; Information quality.

Recebido em 31.03.2015 Aceito em 20.09.2015

\section{Introdução}

$\mathrm{Na}$ atual Sociedade da Informação, investir apenas em recursos de tecnologia da informação e comunicação não é suficiente para obter maior eficácia do ambiente informacional das organizações (DAVENPORT, 2002). Observa-se a importância de ações voltadas à estratégia para o recurso informação, assim como para política e cultura informacional da organização (CHOO, 2011; DAVENPORT; PRUSAK, 1998; DAVENPORT, 2002). O fator humano é crítico, considerando que seus aspectos cognitivos influenciam diretamente no processo de tomada de decisão, principalmente nas análises que exigem reflexão e investigação de informações (LOPES; VALEMTIM, 2014). É importante destacar que a informação é utilizada em três arenas interconectadas da organização: além da tomada de decisão, na criação de significado e na construção do conhecimento (CHOO, 2011). Estas arenas são os principais atrativos para o investimento empresarial no ambiente informacional, e são fortemente dependentes do fator humano, em especial das atitudes e comportamentos com relação à informação.

O componente informacional refere-se à forma como as pessoas lidam com a informação. A mudança de comportamento é de difícil 
gerenciamento, e raramente as empresas percebem e investem na mudança de comportamento e de atitude informacional como meio para apoiar o sucesso de projetos informacionais (DAVENPORT, 2002). A competência informacional é fundamental para a eficiência do trabalhador da sociedade da informação, devendo este possuir um conjunto integrado de conhecimentos ("saber"), habilidades ("saber fazer") e atitudes ("saber agir"), pertinentes à lida com o recurso informação (DE SORDI; AZEVEDO, 2008). A ideia de competência está ligada à capacidade de fazer as coisas acontecerem e de obter resultados efetivos, e tem relação com a quantidade de conhecimento adquirido (BOYATZIS, 2004). A competência, em termos de conhecimento, habilidade e atitude, é melhor observada pela ação e pelo comportamento (CARBONE et al., 2005).

Para Fishbein e Ajzen (1975), as atitudes são preditoras e determinam as intenções em relação ao comportamento. Assim, o comportamento é determinado pela intenção (pela atitude) de se engajar em determinada ação. Pesquisando a relação entre estes dois constructos, Festinger (1957) utilizou a teoria da dissonância cognitiva para discutir e evidenciar o oposto do senso dominante: do impacto dos comportamentos nas atitudes. Para Festinger, as pessoas mudam suas intenções para poderem justificar o que fazem, assim, entende-se a existência de influência mútua entre comportamento e atitude. A atitude informacional está associada ao que a pessoa considera apropriada para com a informação, ou seja, a intenção de se engajar em determinada ação para com a informação. O comportamento informacional é o que a pessoa efetivamente faz com a informação (DAVENPORT, 2002).

As intenções e as ações humanas junto ao recurso informação, respectivamente atitude e comportamento informacional, devem voltar-se à manutenção e ao aprimoramento da qualidade das informações e, por conseqüência, do ambiente informacional da organização. Neste sentido, depreende-se a importância de sensibilizar o crescente conjunto de trabalhadores da informação sobre a necessidade de refletirem sobre o impacto de suas ações na qualidade do recurso informação que manuseiam. Os trabalhadores da informação devem possuir o conhecimento necessário (o "saber"), capaz de perceber a necessidade de realizar a reflexão prévia sobre seus próximos atos junto ao recurso informação (o "saber agir" e responsável). Nesse sentido, esta pesquisa objetiva analisar a utilidade do artefato denominado "Engrenagem para Análise da Qualidade da Informação" em sensibilizar trabalhadores da informação com relação às interdependências entre dimensões de qualidade da informação, evidenciando o risco de se trabalhar com o recurso informação, sem considerar essa perspectiva sistêmica.

O artefato Engrenagem apresenta um conjunto de 32 possíveis relações entre 12 dimensões utilizadas para análise de qualidade da informação (todas descritas na próxima seção), configurando um ambiente de causa e efeito. Por intermédio de uma interface simples, 0 artefato se propõe a sensibilizar e desenvolver a habilidade mental (o "saber fazer"), necessária para a reflexão ampla e sistêmica dos possíveis 
desdobramentos de suas ações junto ao recurso informação. Em termos pragmáticos, o artefato objetiva desenvolver habilidades mentais que auxiliem a promover a atitude informacional da análise de interdependências entre as dimensões de qualidade da informação antes de agir no ambiente informacional, ou seja, trabalhar a atitude informacional a fim de resultar em comportamentos informacionais mais adequados.

A relevância do ambiente informacional para competitividade das organizações como insumo fundamental para geração de conhecimento deve ser considerada para melhor compreensão da importância do comportamento informacional e do artefato proposto. As pesquisas em estratégia empresarial na atual sociedade da informação (GOREY; DOBAT, 1996) destacam que, dentre os recursos da organização, o conhecimento é o que apresenta maior potencial estratégico, devido à dificuldade imposta aos concorrentes para assimilação e imitação deste diferencial (SVEIBY, 2001). Ao contrário dos demais recursos, como os de tecnologia da informação e comunicação, o conhecimento não pode ser facilmente adquirido e colocado prontamente em uso, e os competidores terão que desenvolver experiências similares (ZACK, 1999).

\section{Conceitos necessários ao entendimento do artefato}

$\mathrm{Na}$ literatura, não há consenso quanto à quantidade, escopo e formas de agrupamento para descrever e apresentar as dimensões de qualidade da informação. Eppler (2006) identificou 70 dimensões de qualidade da informação amplamente empregadas na literatura. Variações ocorrem, dependendo da taxionomia adotada entre as muitas disponíveis na academia. Huang, Lee e Wang (1999) descreveram 15 dimensões classificadas em quatro categorias: intrínseca, acessibilidade, contextual e representacional. Para o propósito de sensibilização do usuário, o artefato Engrenagem trabalha como 12 dimensões de qualidade da informação, descritas a seguir:

a)abrangência está associada à porção de conteúdo presente, se contempla tudo que é necessário e somente isso, sem excesso e sem ausência (EPPLER, 2006);

b)atualidade refere-se ao momento da geração ou atualização da informação, que deverá ser adequado à ocasião e a expectativa do usuário (LEE et al., 2002; LOSHIN, 2011);

c)confiabilidade, também denominada por alguns autores como reputação, considerada segundo o nível de credibilidade na fonte da informação (KAHN; STRONG; WANG, 2002; WANG; STRONG, 1996);

d)confidencialidade é assegurar que a informação não será divulgada para pessoas, processos ou dispositivos não autorizados (SCHOU; TRIMMER, 2004); 
e)disponibilidade indica se a informação está acessível para uso imediato. Se a informação é digital, pode ser compreendido como a probabilidade do serviço digital estar disponível (NATH; SINGH, 2010);

f)existência considera a distribuição da informação em termos da quantidade de localidades físicas, digitais e mentais (ENGLISH, 1999).

g)identidade, também denominada por alguns autores de rastreabilidade ou documentação, está associada ao nível de existência e qualidade de metadados (tamanho, data de geração, autor, título, palavras-chave) e metainformações (resumo) que descrevem a informação (LOSHIN, 2011; EPPLER, 2006);

h)integridade, também denominada por alguns autores como "livre de erro", considera se a informação está consistente conforme sua última geração ou atualização, ou seja, se a informação não foi corrompida ou adulterada (KAHN; STRONG; WANG, 2002);

i)originalidade da informação envolve a análise da quantidade de interlocutores, tradutores, redatores, transcritores e demais intermediários que trabalharam com a informação desde sua origem junto à fonte primária (YADAV, 2010);

j)precisão da informação é o nível de detalhamento da informação (abrangência vertical); por exemplo, para uma foto, pode ser a quantidade de pontos por polegada (pixel); para um número, a quantidade de dígitos significativos utilizados (KÖNIGER; REITHMAYER, 1998);

k)raridade, também denominada "equivalência de informação similar", envolve a análise da existência de conteúdos similares disponíveis (HAWKINS, 1999; ENGLISH, 1999);

I)veracidade, associada ao nível de conformidade com um padrão, ou medida padrão, ou valor de controle, e objetiva assegurar que a informação possa ser considerada verdadeira (EPPLER, 2006).

Nesta pesquisa, empregou-se a abordagem Design Science Research $(D S R)$, descrita na seção 4. Gregor e Hevner (2013) afirmam que a seção de revisão da literatura no contexto da DSR deve também apresentar os artefatos já desenvolvidos para resolução de problemas similares. A revisão da literatura, realizada junto aos repositórios de artigos científicos JStor, EBSCO e ProQuest, não identificou artefatos voltados à sensibilização de trabalhadores da informação com relação às interdependências entre dimensões de qualidade da informação. 


\section{0 artefato "Engrenagem para Análise da Qualidade da Informação"}

O artefato "Engrenagem para Análise de Qualidade da Informação" aborda algumas das interdependências, a fim de ilustrar os efeitos sistêmicos entre as dimensões de qualidade da informação. Mais do que a completude e a acurácia plena das interdependências entre dimensões, o artefato se propõe a exemplificar e sensibilizar seus usuários da necessidade de reflexão quanto às interdependências entre dimensões de qualidade da informação antes de decidir por uma intervenção junto ao ambiente informacional da organização. O artefato descreve 32 relações entre dimensões de qualidade da informação, subdivididas em três tipos de relações: a) as técnicas, que consideram aspectos objetivos e racionais e são associadas a aspectos extrínsecos a elas, pertinentes a questões físicas e/ou mecânicas da mídia e do formato utilizados para o armazenamento, processamento, transmissão e apresentação; b) as psíquicas, subjetivas, associadas à percepção do ator envolvido com a informação; e c) as comerciais, associadas à percepção de valor em termos da informação enquanto ativo passível de comercialização. As 32 relações descritas na Engrenagem estão indicadas no Quadro 1, que também informa o sentido da relação, se diretamente ou inversamente proporcional, como também o tipo de relação em questão, se de cunho técnico, psíquico ou comercial.

As 32 relações descritas são algumas dentre as possíveis, sem a pretensão de ser um instrumento totalmente abrangente e conclusivo, bem como os três tipos de relações são indicados a partir do senso comum, sem considerar um segmento de negócio ou área específica da ciência. Pesquisas futuras podem expandir as relações, ou até mesmo invalidar algumas das relações descritas para alguns segmentos de negócios ou áreas específicas da ciência considerada. Não se trata de um artefato exato, mas de um meio para sensibilização e estímulo à reflexão do usuário quanto à dinâmica de interdependência entre as dimensões de qualidade da informação; para tanto, algumas das relações apresentadas devem ser compreendidas e identificadas como verdadeiras no contexto profissional e de experiência de cada usuário.

Quadro 1 - Interdependências entre as dimensões de qualidade da informação descritas na Engrenagem

\begin{tabular}{c|c|c}
\hline Dimensões de Qualidade da Informação Relacionadas & $\begin{array}{c}\text { Sentido da } \\
\text { Relação }\end{array}$ & $\begin{array}{c}\text { Tipo de } \\
\text { Relação }\end{array}$ \\
\hline \hline Abrangência X Disponibilidade & Inversamente & Técnica \\
\hline Abrangência X Raridade & Diretamente & Comercial \\
\hline Abrangência X Veracidade & Inversamente & Técnica \\
\hline Atualidade X Confiabilidade & Diretamente & Psíquica \\
\hline Atualidade X Confidencialidade & Diretamente & Comercial \\
\hline Atualidade X Integridade & Diretamente & Técnica \\
\hline Atualidade X Raridade & Diretamente & Psíquica \\
\hline
\end{tabular}




\begin{tabular}{|c|c|c|}
\hline Atualidade X Veracidade & Diretamente & Psíquica \\
\hline Confiabilidade X Veracidade & Diretamente & Psíquica \\
\hline Confidencialidade X Disponibilidade & Inversamente & Técnica \\
\hline Confidencialidade X Existência & Inversamente & Técnica \\
\hline Confidencialidade X Integridade & Diretamente & Psíquica \\
\hline Confidencialidade X Raridade & Diretamente & Psíquica \\
\hline Disponibilidade X Integridade & Inversamente & Técnica \\
\hline Existência X Atualidade & Inversamente & Técnica \\
\hline Existência X Confidencialidade & Inversamente & Psíquica \\
\hline Existência X Disponibilidade & Diretamente & Técnica \\
\hline Existência X Integridade & Inversamente & Técnica \\
\hline Existência X Raridade & Inversamente & Psíquica \\
\hline Identidade X Confiabilidade & Diretamente & Psíquica \\
\hline Identidade X Disponibilidade & Diretamente & Técnica \\
\hline Integridade X Confiabilidade & Diretamente & Psíquica \\
\hline Integridade $\mathrm{X}$ Veracidade & Diretamente & Técnica \\
\hline Originalidade X Abrangência & Diretamente & Técnica \\
\hline Originalidade X Atualidade & Diretamente & Técnica \\
\hline Originalidade X Veracidade & Diretamente & Técnica \\
\hline Precisão X Confidencialidade & Diretamente & Comercial \\
\hline Precisão X Disponibilidade & Diretamente & Técnica \\
\hline Precisão X Veracidade & Diretamente & Técnica \\
\hline Raridade X Confidencialidade & Diretamente & Comercial \\
\hline Raridade X Existência & Inversamente & Psíquica \\
\hline Veracidade X Confiabilidade & Diretamente & Psíquica \\
\hline
\end{tabular}

Fonte: Elaborado pelos autores.

Ao executar o aplicativo "Engrenagem para Análise de Qualidade da Informação.ppsx"1 a tela inicial apresenta uma introdução sobre o propósito da aplicação; a segunda, as poucas instruções necessárias para operação do aplicativo e, na sequência, a Engrenagem. A estrutura da Engrenagem é composta por uma parte central que descreve 12 dimensões causais, sempre fixas, independentemente de girar à esquerda ou à direita. As dimensões causais indicam a relação de interferência na dimensão citada na parte superior do disco, descrita como "Efeito Desejado", destacada pelo fundo em amarelo. A Figura 1 apresenta o layout da Engrenagem, destacando as dimensões que podem causar incremento ou decréscimo da dimensão citada e destacada no campo "Efeito Desejado", neste caso, a dimensão Disponibilidade. No exemplo em questão, a dimensão Disponibilidade pode ser impactada por cinco dimensões: Precisão, Identidade, Abrangência, Confidencialidade e Existência.

\footnotetext{
${ }^{1}$ Disponível para download em: <http://engrenagemdaqualidade.com.br>. Acesso em: 15 abr. 2015.
} 
Figura 1 - Dimensões que interferem (causas) na dimensão Abrangência (efeito)

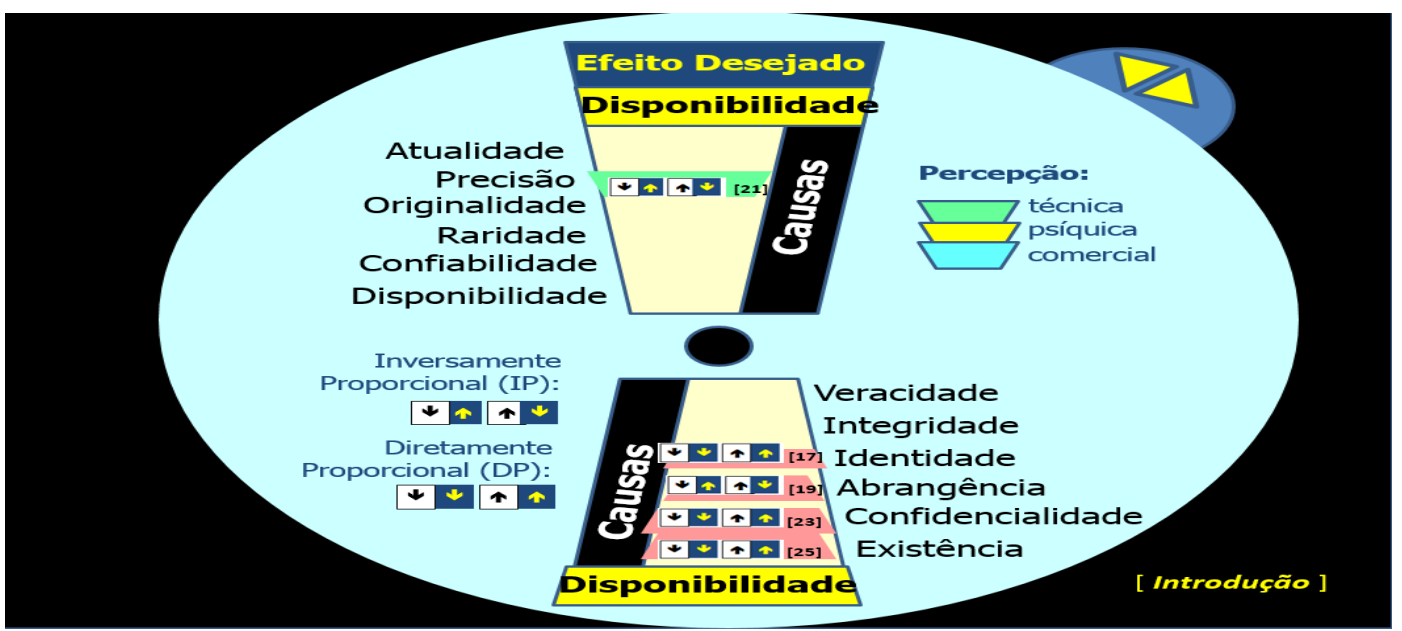

Fonte: Elaborado pelos autores.

As causas associadas ao efeito são descritas por setas, cores e números entre parênteses. Setas no mesmo sentido indicam uma relação diretamente proporcional; setas no sentido contrário indicam uma relação inversamente proporcional. Observa-se que há duas duplas de setas ao lado das dimensões causais, indicando o que acontece com a dimensão destacada em "Efeito Desejado" quando ocorre o movimento de acréscimo ou de decréscimo da dimensão causal. No exemplo da Figura 1, há um conjunto de setas com sentido contrário ao lado da dimensão Precisão, indicando que ações nesta dimensão apresentam efeitos inversamente proporcionais para a dimensão Disponibilidade. Por exemplo, ao tornar uma imagem mais precisa pela alteração da estrutura de conteúdo do formato bitmap (BMP) para o formato Tagged Image File Format (TIFF), aumenta-se o tamanho dos arquivos de imagem, gerando dificuldade na plataforma de processo em função do aumento de tempo necessário para transmissão e apresentação dos conteúdos ao usuário, o que pode ser percebido pelo usuário final como baixa disponibilidade do serviço digital (diminuição da dimensão Disponibilidade). A cor vermelha ao fundo das setas indica que se trata de uma relação de natureza técnica.

Um exemplo de relação diretamente proporcional na Figura 1 ocorre entre as dimensões Existência e Disponibilidade, conforme as duplas de flechas no mesmo sentido. Aumentando a existência da informação (cópias), aumenta-se a disponibilidade; ao diminuir a existência da informação, diminui-se a disponibilidade. Um exemplo e a descrição detalhada das relações podem ser acessados ao clicar no número entre colchetes ao lado de cada relação declarada na Engrenagem. No exemplo descrito acima, entre as dimensões Existência e Disponibilidade, ao lado do conjunto de setas diretamente proporcional, há o número 25 entre colchetes ([25]). Ao clicar nesse número, o software apresentará os textos descritivos e exemplos, conforme apresentado na Figura 2. Após ler 
o texto explicativo, basta clicar na seta rotulada como "voltar" para retornar à Engrenagem.

Figura 2 - Texto descritivo da relação [25] entre a dimensão Existência e a dimensão Disponibilidade

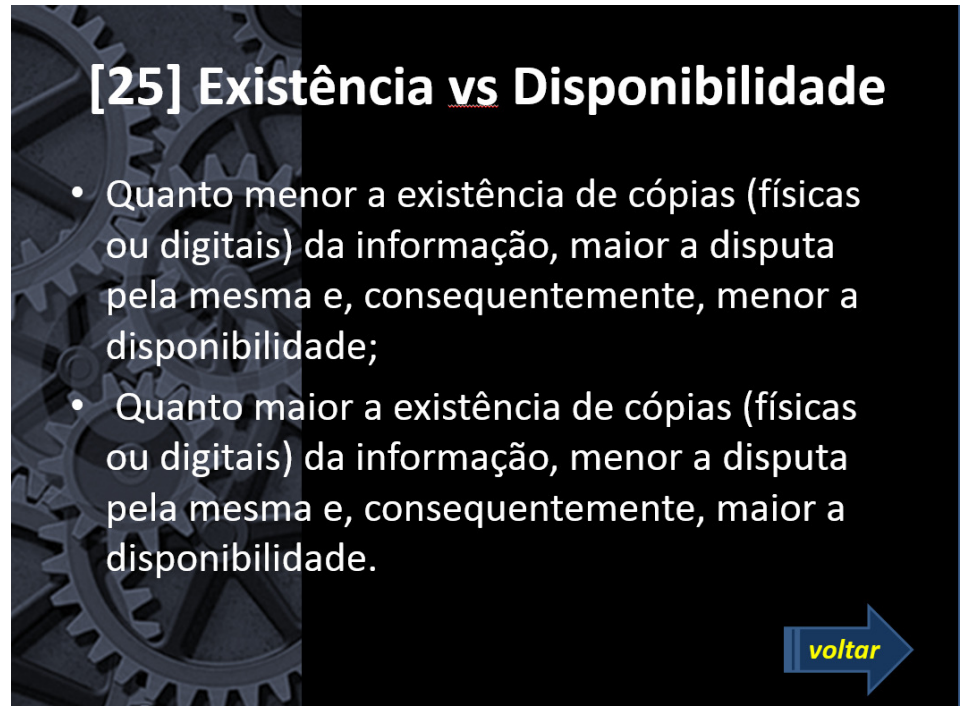

Fonte: Elaborado pelos autores.

Conforme se pode observar, a operação da Engrenagem é bastante simples e intuitiva. Para girar a Engrenagem a fim de exibir outros efeitos (dimensões) desejados, basta clicar em uma das duas setas (triângulos) amarelas presentes na aba localizada no canto superior direito da Engrenagem, conforme se observa na Figura 1. Ao clicar na seta que aponta para direita, o disco girará neste sentido (avança); ao clicar na seta que aponta para a esquerda, seguirá o caminho contrário (volta).

\section{Método da pesquisa}

durante o primeiro quadrimestre de 2014, funcionários e empreendedores das seis empresas foram treinados nos Segundo Hevner et al. (2004, p. 81, tradução nossa) "design science research (DSR) aborda problemas importantes, ainda não resolvidos, de forma única e inovadora, ou problemas já resolvidos, porém de forma mais eficaz". Quanto à díade "problema importante não resolvido" e "forma única e inovadora" têm-se para esta pesquisa: a) a necessidade de sensibilizar o crescente contingente de trabalhadores da informação quanto ao impacto de suas ações para a qualidade do recurso informação manuseado, bem como do ambiente informacional da organização como um todo, sendo isto mandatório para que as organizações possam extrair maior valor de seus ambientes informacionais; e b) a escassez de ferramentas organizacionais voltadas ao comportamento informacional, expressando a raridade do artefato proposto, e também sua característica inovadora em utilizar exemplos do cotidiano como estímulo à reflexão das interdependências entre as dimensões de qualidade da informação. 
Gregor e Hevner (2013) classificam a DSR quanto a) aos níveis de contribuições possíveis e b) aos tipos de conhecimento gerados. As contribuições são classificadas em três níveis: o nível um é denominado de "situated implementation of artifact" e, costumeiramente, caracterizase pela operação de um novo software ou processo; os níveis dois e três são, respectivamente, "nascent design theory" e "well-developed design theory". A contribuição de nível um é caracterizada, segundo Gregor e Hevner (2013, p. 341), pela "pesquisa que contribua com a demonstração de um novo artefato que incorpore teorias e ideias até então não articuladas, formalizadas e completamente compreendidas". O método e o software desenvolvidos, testados e disponíveis com a "Engrenagem para Análise da Qualidade da Informação", caracterizam as contribuições desta pesquisa como sendo de nível um. Quanto aos tipos de conhecimentos gerados pela DSR, estes podem ser: invenção, exploração, aprimoramento e exaptação (GREGOE; HEVNER, 2014).

O conhecimento do tipo Aprimoramento concilia novas soluções para problemas já conhecidos, sendo o tipo de conhecimento gerado pela pesquisa descrita neste artigo: a proposição de um artefato inovador, a Engrenagem, para um problema já conhecido, e a necessidade de ter o comportamento informacional e de pensar a qualidade da informação sistemicamente, ou seja, considerando a interdependência entre suas dimensões.

O conhecimento do tipo Aprimoramento da DSR está associado a contribuições prescritivas, do tipo "como" funciona o artefato (GREGOR; HEVNER, 2013). O conhecimento prescritivo explicita como fazer algo e, além das características do artefato, fornece as normas tecnológicas e as regras que determinam como alcançar um resultado desejado, em uma situação particular, com a utilização do mesmo (IIVARI, 2007; KUECHLER; VAISHNAVI, 2008). O resultado desejado está associado à característica da utilidade, premissa central da DSR. Contrário ao paradigma da ciência positivista dominante que busca encontrar "o que é verdade", a DSR busca criar "o que é efetivo" (HEVNER et al., 2004). A verificação da utilidade do artefato é destacada como uma das sete diretrizes da DSR (HEVNER et al., 2004): a) o objeto de estudo deve ser um artefato ("design as an artifact"); b) o problema que o artefato se propõe a resolver deve ser relevante ("problem relevance"); c) a avaliação da utilidade do artefato deve ser rigorosa ("design evaluation"); d) deve haver contribuição efetiva para a área de conhecimento do artefato ("research contributions"); e) a pesquisa deve ser rigorosa ("research

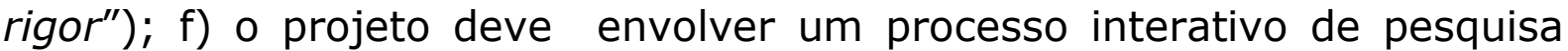
com testes ("design as a search process"); e g) deve existir a comunicação dos resultados, inclusive para o público-alvo do artefato ("communication of research").

Para a avaliação da utilidade do artefato, foram convidadas seis micro e pequenas empresas (MPE), voltadas para produtos e serviços intensivos em informação, a participar do experimento com o artefato. Optou-se por MPE em função do maior controle do empreendedor em 
termos de assegurar a participação dos funcionários nos dois momentos de interação com os pesquisadores (capacitação e coleta de dados), bem como por ser mais viável o acompanhamento dos comportamentos informacionais dos funcionários pelo empreendedor após o evento de treinamento e disponibilização do artefato. Os critérios utilizados para definição de MPE foram os do Serviço Brasileiro de Apoio às Micro e Pequenas Empresas (SERVIÇO BRASILEIRO DE APOIO ÀS MICRO E PEQUENAS EMPRESAS - SEBRAE, 2011): ter no máximo, 19 funcionários na indústria, ou 9 na área de comércio e serviços.

Trinta e três funcionários de seis empresas compuseram a amostra da pesquisa. As MPE da amostra estão associadas a seis diferentes segmentos, todas fazendo uso intensivo do recurso informação, sendo: uma empresa da área de comunicação (jornal), uma da área de serviços topográficos e geoprocessamento, uma da área de publicidade e propaganda, uma de ensino profissionalizante para área de estética, uma na área de design e criação de produtos e uma da área de desenvolvimento de softwares. A coleta de dados em campo ocorreu em três momentos:

a)conceitos envoltos e na utilização do software "Engrenagem para Análise de Qualidade da Informação". Os treinamentos foram realizados na sede de cada MPE e tiveram a duração aproximada de três horas cada. O software da Engrenagem foi instalado nos computadores dos funcionários, e uma versão física em papel (banner) foi fixado em ambiente de ampla circulação dos trabalhadores. Antes do treinamento na operação do software Engrenagem, logo após a conceituação das dimensões de qualidade da informação e de suas relações de interdependências, realizou-se um exercício voltado à autorreflexão do funcionário com relação às suas atitudes (considerar/pensar em) e comportamentos (agir/executar) no ambiente informacional da empresa, para cada uma das 32 relações de interdependências entre dimensões de qualidade da informação. Destaca-se que este instrumento não foi utilizado para fins avaliativos, mas com o objetivo de gerar maior discernimento e reflexão dos funcionários com cada uma das dimensões de qualidade da informação e suas interdependências. $O$ instrumento utilizado para essa reflexão está presente no Apêndice $A$;

b)Quarenta e cinco dias após a realização do treinamento, procedeu-se a coleta de dados junto aos funcionários das empresas. Os funcionários responderam, individualmente, um questionário que solicitava a análise do comportamento informacional apresentado durante os últimos 45 dias, descrevendo e exemplificando as alterações percebidas, segundo a perspectiva de cada uma das dimensões de 
qualidade da informação. O questionário utilizado para coleta destes dados está presente no Apêndice B;

c)Foram elaboradas planilhas por empresa, indicando as alterações de comportamento declaradas pelos funcionários para cada uma das dimensões de qualidade da informação. Em seguida, retornou-se às empresas em um terceiro momento para realização de entrevista semiestruturada com o empreendedor, a fim de observar a percepção dele com relação à mudança de comportamento informacional indicada pelos funcionários. As percepções declaradas pelos funcionários foram comparadas com as percepções de mudanças de comportamentos observadas pelos empreendedores, tendo sido realizado individualmente para cada um dos funcionários da empresa. Os pontos de concordância e de divergência foram identificados e discutidos com os empreendedores e, assim, identificaram-se as informações de alteração de comportamento simétricas, ou seja, as percebidas e informadas tanto pelo empreendedor quanto pelo funcionário.

\section{Resultados}

Para validar os dados coletados em campo, procedeu-se uma análise de consistência lógica entre as respostas fornecidas pelo funcionário, ou seja, se elas estavam coerentes entre si conforme os princípios sistêmicos das inter-relações entre as dimensões de qualidade da informação. Considerou-se a análise cruzada entre três relações previstas no artefato e descritas no Quadro 1, entre as dimensões existência e disponibilidade, existência e confidencialidade, e existência e raridade. Observou-se nos dados da coleta que, no respondente que indicou aumento na disponibilidade para facilitar o acesso aos demais funcionários da empresa, diminuíram os comportamentos associados à dimensão confidencialidade. Mais um aspecto analisado é que os funcionários que relataram diminuição na existência da informação relataram aumento de comportamentos associados à dimensão confidencialidade. Outra análise feita para verificar a coerência nas respostas foi a das justificativas apresentadas pelos respondentes; por exemplo, as situações em que declarou-se o aumento de ações associadas à dimensão existência se justificaram em função da segurança (backup); o aumento de ações comportamentais atreladas à raridade se justificaram em função da produção de conteúdos inovadores. Dessa forma, os dois questionários associados a cada um dos 33 profissionais tiveram suas respostas validadas, demonstrando coerência e consistência. 
A Tabela 1 apresenta a posição consolidada das dimensões de qualidade da informação que apresentaram maior alteração de comportamento informacional segundo o relato dos 33 funcionários. Observa-se que as dimensões mais citadas foram: existência, confiabilidade, abrangência e atualidade. Dentre esta amostra, 22 dos 33 funcionários (67\%) indicaram modificação de comportamento com relação à dimensão existência, sendo que, destes, 20 relataram aumento na manifestação de seus comportamentos e apenas 2 relataram diminuição. Para a dimensão confiabilidade, verificaram-se 20 relatos, e todos indicaram aumento na manifestação de seus comportamentos. Para a dimensão abrangência, observaram-se 19 relatos manifestando mudança, sendo que todos também foram de aumento na manifestação desses comportamentos. Na dimensão Atualidade, 17 relatos de mudança indicaram um aumento na manifestação de seus comportamentos.

Tabela 1 - Dimensões de qualidade da informação mais impactada segundo os próprios funcionários

\begin{tabular}{|c|c|c|c|c|c|}
\hline \multirow[b]{2}{*}{ Dimensão } & \multirow{2}{*}{$\begin{array}{l}\text { Percentual dos } 33 \\
\text { funcionários da } \\
\text { amostra que } \\
\text { relataram } \\
\text { Modificação de } \\
\text { Comportamento }\end{array}$} & \multicolumn{4}{|c|}{$\begin{array}{l}\text { Distribuição do Nível de Modificação (dos } \\
\text { funcionários que relataram modificação) }\end{array}$} \\
\hline & & $\begin{array}{c}-2 \\
\text { Diminuiu } \\
\text { Muito }\end{array}$ & $\begin{array}{c}-1 \\
\text { Diminuiu } \\
\text { Pouco }\end{array}$ & $\begin{array}{c}1 \\
\text { Aumentou } \\
\text { Pouco }\end{array}$ & $\begin{array}{c}2 \\
\text { Aumentou } \\
\text { Muito }\end{array}$ \\
\hline $\begin{array}{l}\text { Existência } \\
\text { Confiabilidade } \\
\text { Abrangência } \\
\text { Atualidade } \\
\text { Integridade } \\
\text { Identidade } \\
\text { Veracidade } \\
\text { Originalidade } \\
\text { Confidencialidade } \\
\text { Disponibilidade } \\
\text { Raridade } \\
\text { Precisão }\end{array}$ & $\begin{array}{l}67 \% \\
61 \% \\
58 \% \\
52 \% \\
39 \% \\
39 \% \\
36 \% \\
33 \% \\
33 \% \\
33 \% \\
21 \% \\
18 \%\end{array}$ & & $6,1 \%$ & $\begin{array}{r}39,39 \% \\
33,33 \% \\
42,42 \% \\
42,42 \% \\
30,30 \% \\
30,30 \% \\
30,30 \% \\
27,27 \% \\
21,21 \% \\
24,24 \% \\
18,18 \% \\
9,09 \%\end{array}$ & $\begin{array}{c}21,21 \% \\
27,27 \% \\
15,15 \% \\
9,09 \% \\
9,09 \% \\
9,09 \% \\
6,06 \% \\
6,06 \% \\
9,09 \% \\
9,09 \% \\
3,03 \% \\
9,09 \%\end{array}$ \\
\hline
\end{tabular}

Fonte: Dados da pesquisa.

Estabelecendo um paralelo com Batini et al.(2009), que analisaram as dimensões em referência à qualidade dos dados, percebemos que, das quatro dimensões mais citadas no presente estudo, duas também se fizeram presentes entre as mais citadas na pesquisa de Batini et al. (2009): Abrangência e Atualidade. Isso demonstra a importância dessas dimensões por meio da pesquisa de campo, tanto para praticantes, quanto para acadêmicos-pesquisadores. Também foram citadas as dimensões Integridade e Identidade com relato de 13 funcionários cada, a dimensão Veracidade com 12 e as dimensões Originalidade, 
Confidencialidade e Disponibilidade com 11 relatos. Desse grupo, excetuando-se a dimensão Confidencialidade, que apresentou uma manifestação de redução de comportamento (uma dentre onze), todas as demais dimensões apresentaram aumento nas manifestações de comportamento relatadas pelos funcionários impactados.

Dos 159 relatos de modificação de comportamento relatados pelos funcionários, 156 foram de aumento na manifestação dos comportamentos, ou seja, os funcionários relataram que passaram a fazer mais do que faziam antes da capacitação. Apenas 3, dos 159 relatos, foram de diminuição na manifestação dos comportamentos, indicando que, nas empresas que participaram, grande parte dos funcionários envolvidos no presente estudo não executava ou executava pouco os comportamentos relacionados com as dimensões. Verificou-se ainda que as dimensões abrangência, atualidade, confiabilidade, confidencialidade, existência e integridade tiveram relatos de mudança de comportamentos em todas as empresas participantes.

Além das mudanças de comportamentos relatadas pelos funcionários, algumas delas foram percebidas e testemunhadas pelos empreendedores das empresas participantes, caracterizando uma relação simétrica entre relatos do funcionário e do empreendedor da empresa. Isso foi possível pela validação das informações relatadas pelos funcionários junto ao empreendedor da MPE, procedimento este executado por intermédio da entrevista semiestruturada. Com o procedimento, observou-se tanto relações assimétricas, ou seja, comportamentos relatados pelos funcionários e não confirmados pelo empreendedor, quanto relações simétricas, percebidas por ambos. As relações simétricas são mais importantes para os fins desta pesquisa, pois caracterizam informações mais fidedignas, já que foram relatadas pelos funcionários e confirmadas pelos empreendedores. Porém, é valido relatar que não se pode afirmar que as relações assimétricas não sejam fidedignas. A Tabela 2 demonstra as dimensões em que se percebeu simetria caracterizada pela mudança de comportamento informacional relatada pelo funcionário $e$, posteriormente, confirmada pelo testemunho do empreendedor. 
Tabela 2 - Dimensões em que os funcionários relataram mudanças e que foram confirmadas pelo empreendedor

\begin{tabular}{|c|c|c|c|c|c|c|c|c|c|c|c|c|c|c|c|}
\hline \multirow[t]{2}{*}{ Dimensões } & \multicolumn{2}{|c|}{ 兽 } & \multicolumn{2}{|c|}{ U⿺辶寸 } & \multicolumn{2}{|c|}{ 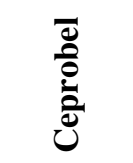 } & \multicolumn{2}{|c|}{ 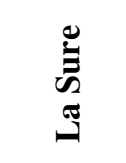 } & \multicolumn{2}{|c|}{ 遏 } & \multicolumn{2}{|c|}{ 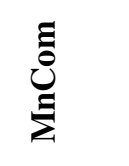 } & \multicolumn{3}{|c|}{ Totais Gerais } \\
\hline & $\sum_{i}$ & $\sum_{z}^{\infty}$ & $\sum$ & $\sum^{\infty}$ & $\sum$ & $\sum^{\infty}$ & $\sum$ & $\sum^{\infty}$ & $\sum$ & $\sum^{\infty}$ & $\sum$ & $\sum_{z}^{\infty}$ & $\sum$ & $\sum^{\infty}$ & $\begin{array}{c}\% \\
\text { simetr }\end{array}$ \\
\hline Confiabilidade & 3 & 3 & 5 & 3 & 1 & 1 & 1 & 1 & 4 & 4 & 5 & 5 & 20 & 17 & $85 \%$ \\
\hline Confidencialidade & 2 & 0 & 2 & 1 & 1 & 1 & 1 & 1 & 2 & 2 & 3 & 3 & 11 & 8 & $73 \%$ \\
\hline Identidade & - & - & 5 & 5 & 4 & 1 & - & - & 2 & 1 & 3 & 2 & 13 & 9 & $69 \%$ \\
\hline Integridade & 1 & 0 & 3 & 0 & 3 & 3 & 3 & 2 & 2 & 2 & 2 & 2 & 13 & 9 & $69 \%$ \\
\hline Abrangência & 2 & 1 & 7 & 4 & 4 & 3 & 2 & 1 & 1 & 1 & 3 & 3 & 19 & 13 & $68 \%$ \\
\hline Atualidade & 1 & 0 & 3 & 2 & 2 & 0 & 4 & 2 & 3 & 3 & 3 & 2 & 17 & 9 & $53 \%$ \\
\hline Existência & 2 & 0 & 5 & 3 & 2 & 1 & 4 & 1 & 4 & 2 & 5 & 4 & 22 & 11 & $50 \%$ \\
\hline Veracidade & - & - & 5 & 1 & - & - & - & - & 3 & 2 & 4 & 3 & 12 & 6 & $50 \%$ \\
\hline Disponibilidade & 1 & 0 & 3 & 2 & - & - & - & - & 3 & 1 & 4 & 1 & 11 & 4 & $36 \%$ \\
\hline Originalidade & - & - & 4 & 2 & 1 & 0 & - & - & 1 & 1 & 4 & 1 & 11 & 4 & $36 \%$ \\
\hline Raridade & - & - & 2 & 1 & 2 & 0 & - & - & 1 & 1 & 2 & 0 & 7 & 2 & $29 \%$ \\
\hline Precisão & - & - & 4 & 0 & - & - & - & - & - & - & 2 & 1 & 6 & 1 & $15 \%$ \\
\hline \multirow{2}{*}{$\%$ simetria } & 12 & 4 & 48 & 24 & 20 & 10 & 15 & 8 & 26 & 20 & 40 & 27 & 162 & 93 & $57,5 \%$ \\
\hline & \multicolumn{2}{|c|}{$25 \%$} & \multicolumn{2}{|c|}{$50 \%$} & \multicolumn{2}{|c|}{$50 \%$} & \multicolumn{2}{|c|}{$53 \%$} & \multicolumn{2}{|c|}{$77 \%$} & \multicolumn{2}{|c|}{$67,5 \%$} & \multicolumn{2}{|c|}{$57,5 \%$} & \\
\hline
\end{tabular}
Fonte: Dados da pesquisa.

Na Tabela 2, observou-se que a dimensão da qualidade que mais apresentou mudanças comportamentais dos funcionários, validadas pelo empreendedor, foi a confiabilidade. Nessa dimensão, 17 funcionários que declararam modificações no comportamento tiveram essas mudanças confirmadas pelo empreendedor. Estabelecendo um paralelo com a análise de redes sociais, laços podem ser transações, conexões ou interações entre os atores (WASSERMAN, 1994). Assim, verifica-se, para dimensão confiabilidade, uma forte relação entre a mudança relatada pelo funcionário e a observação do empreendedor, caracterizando laços fortes. Dessa forma, as relações simétricas são referentes às dimensões de qualidade da informação mais perceptíveis ao empreendedor. Outra dimensão que caracterizou relações simétricas entre os relatos dos funcionários e dos empreendedores foi a abrangência. Nessa dimensão, 13 funcionários declararam modificações que foram confirmadas pelos empreendedores, ocorrendo laços fortes. As dimensões que demonstraram menor número de relatos de funcionário confirmados pelos empreendedores foram disponibilidade e originalidade (cada uma com quatro relatos), raridade (com dois relatos) e precisão (com apenas um relato). 


\section{Análises e discussões sobre a utilidade do artefato}

Estabelecendo uma relação entre as dimensões mais susceptíveis a mudanças e as mais simétricas, percebe-se que nem todos os comportamentos relatados pelos funcionários foram observados e validados pelos empreendedores. A Tabela 2 demonstra a diferença entre as relações assimétricas (que não foram validadas pelo empreendedor) e as simétricas (validadas pelo empreendedor). Oito, das doze dimensões estudadas, apresentaram $50 \%$ ou mais de respostas simétricas entre funcionários e empreendedores (confiabilidade, identidade, integridade, abrangência, confidencialidade, atualidade, existência e veracidade). Uma explicação para essa diferença é o fato de algumas dimensões serem mais abstratas e menos perceptíveis ao observador que está a acompanhar as ações comportamentais, neste caso, o empreendedor da MPE. Essas dimensões acabam demonstrando menor grau de simetria do que as outras. Entre as menos simétricas, conforme Tabela 2, destacam-se as dimensões precisão (com 16,6\% de simetria), raridade (com 28,5\%), disponibilidade e originalidade (ambas com 36\% de simetria).

Foram elaborados dois rankings contendo as dimensões de qualidade da informação mais suscetíveis à mudança de comportamento, um segundo com a percepção dos funcionários e outro considerando apenas as informações simétricas entre funcionário e empreendedor. As posições das dimensões de qualidade da informação perante estes dois rankings estão descritas na Tabela 3. Apenas duas dimensões estão entre as cinco primeiras considerando os dois rankings: confiabilidade e abrangência. Nas últimas quatro posições, ou seja, entre as que apresentam comportamento menos impactado, identificaram-se três dimensões independentemente do ranking: disponibilidade, raridade e precisão.

Tabela 3 - Grau de coerência entre o relato dos funcionários e a percepção dos empreendedores

\begin{tabular}{|c|c|c|c|}
\hline Dimensão & $\begin{array}{c}\text { Posição considerando } \\
\text { relato dos } \\
\text { funcionários }\end{array}$ & $\begin{array}{l}\text { Posição considerando } \\
\text { relatos simétricos entre } \\
\text { funcionários e } \\
\text { empreendedores }\end{array}$ & Grau de Coerência \\
\hline Abrangência & $3^{\circ}$ & $4^{\circ}$ & -1 \\
\hline Atualidade & $4^{\circ}$ & $6^{\circ}$ & -2 \\
\hline Confiabilidade & $2^{\circ}$ & $1^{\circ}$ & 1 \\
\hline Confidencialidade & $9^{\circ}$ & $2^{\circ}$ & 7 \\
\hline Disponibilidade & $10^{\circ}$ & $9^{\circ}$ & 1 \\
\hline Existência & $1^{\circ}$ & $7^{\circ}$ & -6 \\
\hline Identidade & $6^{\circ}$ & $2^{\circ}$ & 4 \\
\hline Integridade & $5^{\circ}$ & $3^{\circ}$ & 2 \\
\hline Originalidade & $8^{\circ}$ & $10^{\circ}$ & -2 \\
\hline Precisão & $12^{\circ}$ & $12^{\circ}$ & 0 \\
\hline Raridade & $11^{\circ}$ & $11^{\circ}$ & 0 \\
\hline Veracidade & $7^{\circ}$ & $8^{\circ}$ & -1 \\
\hline
\end{tabular}

Fonte: Dados da pesquisa. 
Para cada dimensão de qualidade da informação calculou-se a diferença obtida entre os dois rankings, valor denominado como Grau de Coerência e descrito na última coluna da Tabela 3. O grau de coerência evidencia que algumas dimensões mantiveram-se nas mesmas posições ou oscilaram pouco, como a confiabilidade, que oscilou apenas uma posição, e a raridade e precisão, que mantiveram a posição. Por outro lado, verificam-se dimensões que oscilaram muitas posições, como a existência, que oscilou seis posições. Com até um 1 de desvio, tivemos 6 dimensões; se considerarmos até 2 graus de desvio, temos 9, das 12 dimensões. Apenas 3 dimensões diferenciaram-se significativamente em termos de percepção do funcionário e do empreendedor: confidencialidade, existência e identidade.

A Figura 3, demonstra como as dimensões de qualidade da informação se localizam em um eixo " $y$ " (percepção de mudança, relatada apenas pelo funcionário) e em um eixo " $x$ " (ocorrência de mudança, relatada tanto pelo funcionário quanto pelo empreendedor). Por exemplo, as dimensões localizadas no quadrante I do gráfico (canto superior esquerdo) são pouco mutáveis, ou seja, pouco sensíveis ao uso do artefato em termos de mudança de comportamento; porém, as poucas alterações são mais perceptíveis ao olhar de terceiros, no caso estudado, os empreendedores. Nesta situação, encontram-se as dimensões confidencialidade, identidade, integridade e veracidade. No quadrante II (canto superior direito) estão as dimensões de qualidade da informação que agregam maior valor e justificam o uso do artefato, pois indica as dimensões com alta ocorrência de mudança e alta percepção da mudança. No quadrante II estão localizadas as dimensões confiabilidade, abrangência, atualidade e existência. O quadrante III (canto inferior esquerdo) é o de menor valor em termos do emprego do artefato, pois indica as dimensões com baixa ocorrência de mudança e baixa percepção da mudança. Para o contexto estudado, no quadrante III encontram-se as dimensões raridade, disponibilidade, originalidade e precisão.

Figura 3 - Percentual dos 33 funcionários que declararam a mudança versus percentual das mudanças simétricas, percebidas pelos funcionários e pelos empreendedores

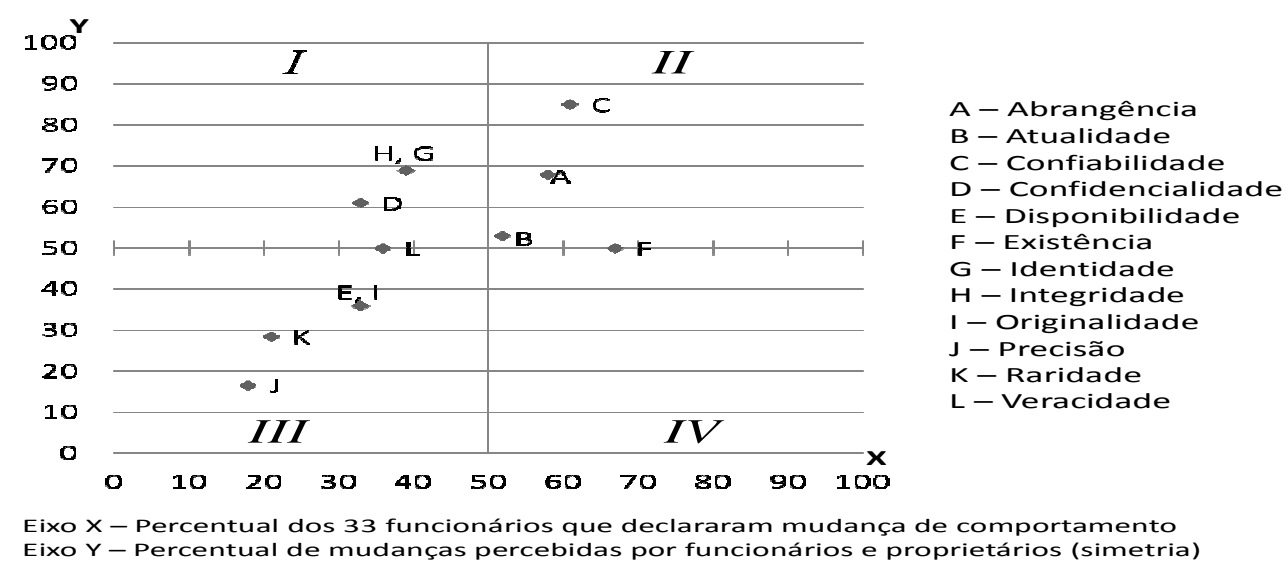

Fonte: Dados da pesquisa. 
Percebe-se que, por intermédio da Figura 3, caso o empresário das MPE intensivas em conhecimento queira observar mudanças no comportamento informacional em curto prazo, as dimensões mais recomendadas são as localizadas no quadrante II (canto superior direito): abrangência, confiabilidade, atualidade e existência. Dessa forma, a capacitação em conjunto com o artefato "Engrenagem para Análise da Qualidade da Informação" demonstra ser mais eficaz em curto espaço de tempo em casos que o empresário de MPE intensiva em conhecimento tenha problemas de comportamento informacional relacionados com algumas dessas dimensões. Porém, é importante salientar que os dados da Figura 3 constituem uma percepção inicial, e pesquisas futuras devem aprofundar o entendimento, considerando a subjetividade dos resultados encontrados em seis empresas, com a participação de 33 funcionários ao todo.

Não se pode afirmar que as dimensões raridade, disponibilidade, originalidade e precisão são as menos susceptíveis à mudança e são as menos observáveis (principalmente a última afirmação), considerando que elas podem não terem sido observadas ou mesmo manifestadas em função do curto espaço de tempo decorrido entre uma coleta e outra: foram 45 dias de intervalo entre a capacitação e o retorno. $O$ fato observado que demonstra uma lógica é que, quanto mais ocorrências relatadas pelos funcionários para uma determinada dimensão de qualidade da informação, mais observável ao empreendedor, isto é, maior a simetria entre as respostas do funcionário e do empreendedor.

\section{Conclusão}

Pesquisas com abordagem DSR voltam-se para a utilidade de artefatos. Nesta pesquisa, evidenciou-se que o artefato "Engrenagem para Análise da Qualidade da Informação" foi eficaz na promoção da mudança de comportamento informacional dos 33 empregados das seis MPE. As evidências principais estão caracterizadas pelas 33 pessoas que participaram da pesquisa: todas apresentaram alteração de comportamento informacional. Relatou-se um total de 162 comportamentos modificados, sendo que 57,5\% deles também foram percebidos e relatados pelos empreendedores, evidenciando maior acurácia desta informação. Considerando o treinamento provido no primeiro contato com os funcionários das seis MPE, há a necessidade de uma análise conclusiva mais abrangente, abrangendo estes dois recursos empregados: a difusão de informação sobre interdependências entre dimensões de qualidade da informação e a disponibilidade de recursos (o artefato) para análise e reflexão desta dinâmica sistêmica, que colaboram com a promoção de mudanças de comportamentos informacionais dos trabalhadores da informação.

Tão importante quanto a utilidade demonstrada é a relevância em termos do contexto organizacional no qual 0 artefato se aplica. 0 
comportamento informacional é um dos grandes desafios das empresas intensivas em conhecimento, que dependem muito do desempenho e do comportamento dos trabalhadores da informação. A "Engrenagem para Análise da Qualidade da Informação" é um recuso não apenas de difusão do conhecimento, mas de apoio e estímulo à reflexão. Considerar as interdependências entre as dimensões de qualidade da informação é fundamental ao processo de análise e seleção dentre as possíveis ações junto ao recurso informação. Levar em conta as relações sistêmicas entre as dimensões evita a ocorrência de análises parciais e simplistas, bem como auxilia na redução de eventos prejudiciais ao ambiente informacional da organização.

A pesquisa indicou algumas dimensões menos suscetíveis a mudanças ou, em última instância, associadas a mudanças de comportamento menos observáveis por terceiros. Este é o caso das dimensões localizadas no terceiro quadrante da Figura 3: raridade, disponibilidade, originalidade e precisão. Porém, é necessário considerar as limitações de tempo das observações realizadas nesta pesquisa, como a coleta de dados realizada 45 dias após a data da capacitação dos funcionários no artefato. Isso pode ter interferido, já que algumas dimensões de qualidade da informação estão associadas a eventos com menor frequência de ocorrência e que necessitam um período maior de observação. Este é o caso da dimensão raridade, associada a eventos geralmente escassos nas organizações, como por exemplo o desenvolvimento de conteúdos raros e inovadores, tanto no contexto interno quanto externo à organização. Dessa forma, recomenda-se que pesquisas futuras que utilizem 0 artefato considerem a ampliação do intervalo de tempo entre os momentos da capacitação no software e o retorno para coleta de dados comportamentais.

\section{Referências}

BATINI, C. et al. Methodologies for data quality assessment and improvement. ACM Computing Surveys, v. 41, n. 3, p. 1-52, 2009.

BOYATZIS, R. E. Self-directed learning. Executive Excellence, v. 21, n. 2, p. $11-12,2004$.

CARBONE, P. P. et al. Gestão por competências e gestão do conhecimento. Rio de Janeiro: Editora FGV, 2005.

CHOO, C. W. A organização do conhecimento: como as organizações usam a informação para criar significado, construir conhecimento e tomar decisões. 3. ed. São Paulo: SENAC Editora, 2011.

DAVENPORT, T. H. Ecologia da informação: por que só a tecnologia não basta para o sucesso na era da informação. São Paulo: Futura, 2002.

DAVENPORT, T. H.; PRUSAK, L. Conhecimento empresarial. Rio de Janeiro: Campus, 1998. 
DE SORDI, J. O.; AZEVEDO, M. C. Análise de competências individuais e organizacionais associadas à prática de gestão do conhecimento. Revista Brasileira de Gestão de Negócios, v. 10, n. 29, p. 391-407, 2008.

ENGLISH, L. P. Improving data warehouse and business information quality. New York, NY: John Wiley \& Sons, 1999.

EPPLER, M. J. Managing information quality. increasing the value of knowledge-intensive products and processes. 2. ed. New York, NY: Springer, 2006.

FESTINGER, L. A. Theory of cognitive dissonance. Stanford, CA: Stanford University Press, 1957.

FISHBEIN, M.; AJZEL, L. Belief, attitude, intention and behavior. Reading, MA: Addison Wesley, 1975.

GOREY, R.M.; DOBAT, D.R. Managing in the Knowledge Era. The Systems Thinker, v. 7, n. 8, p. 1-5, 1996.

GREGOR, S.; HEVNER, A. R. Positioning and presenting design science research for maximum impact. MIS Quarterly, v. 37, n. 2, p. 337-355, 2013.

HAWKINS, D. T. What is credible information? Online, v. 23, n. 5, p. 8689, 1999.

HEVNER, A.R. et al. Design science in Information Systems Research. MIS Quarterly, v. 28, n. 1, p. 75-105, Mar. 2004.

HUANG, K. T.; LEE, Y. W.; WANG, R. Y. Quality information and Knowledge. New York, NY: Prentice-Hall, 1999.

IIVARI, J. A paradigmatic analysis of information systems as a design science. Scandinavian Journal of Information Systems, v. 19, n. 2, p. 3964, 2007.

KAHN, B. K.; STRONG, D. M.; WANG, R. Y. Information quality benchmarks: Product and Service Performance. Communications of the ACM, v. 45, n. 4, p. 184-192, 2002

KONIGER, P.; REITHMAYER, W. Management unstrukturierter Informationen. Frankfurt, DE: Campus Verlag, 1998.

KUECHLER, B.; VAISHNAVI, V. Theory development in design science research: anatomy of a research project. European Journal of Information Systems, v. 17, n. 5, p. 489-504, 2008.

LEE, Y. W. et al. AIMQ: a methodology for information quality assessment. Information \& Management, v. 40, n. 2, p. 133-146, 2002.

LOPES, E. C.; VALENTIM, M. L. P. Information search behavior: proposal of study with investors in the stock market. Technology and Investment, v. 6, n. 1, p. 8-16, 2014.

LOSHIN, D. The Practitioner's guide to data quality improvement. Burlington, MA: Morgan Kaufmann, 2011. 
NATH, A.; SINGH, R. Evaluating the performance and quality of web services in electronic marketplaces. E-Services Journal, v. 7, n. 1, p. 43$59,2010$.

SCHOU, C. D.; TRIMMER, K. J. Information assurance and security. Journal of Organizational and End User Computing, v. 16, n. 3, p. i-vii, 2004.

SERVIÇO BRASILEIRO DE APOIO ÀS MICRO E PEQUENAS EMPRESAS (SEBRAE). Departamento Intersindical de Estatística e Estudos Socioeconômicos (DIEESE). Anuário do Trabalho na micro e Pequena Empresa 2010/2011. Brasília: SEBRAE, 2011.

SVEIBY, K. A knowledge-based theory of the firm to guide in strategy formulation. Journal of Intellectual Capital, v. 2, n. 4, p. 344-358, 2001.

WANG, R. Y; STRONG, D. M. Beyond accuracy: what data quality means to data consumers. Journal of Management Information Systems, v. 12, n. 4, p. 5-33, 1996.

WASSERMAN, S.; FAUST, K. Social network analysis: methods and applications. Cambridge, EUA: Cambridge University Press, 1994.

YADAV, S. B. A conceptual model for user-centered quality information retrieval on the world wide web. Journal of Intelligent Information Systems, v. 35, n. 1, p. 91-121, 2010.

ZACK, M. H. Developing a knowledge strategy. California Management Review, v. 41, n. 3, p. 125-145, 1999. 


\section{Apêndice A - Instrumento para reflexão dos funcionários com relação às suas atitudes (considerar/pensar em) e comportamentos (executar/agir) associados às interdependências entre as dimensões de qualidade da informação}

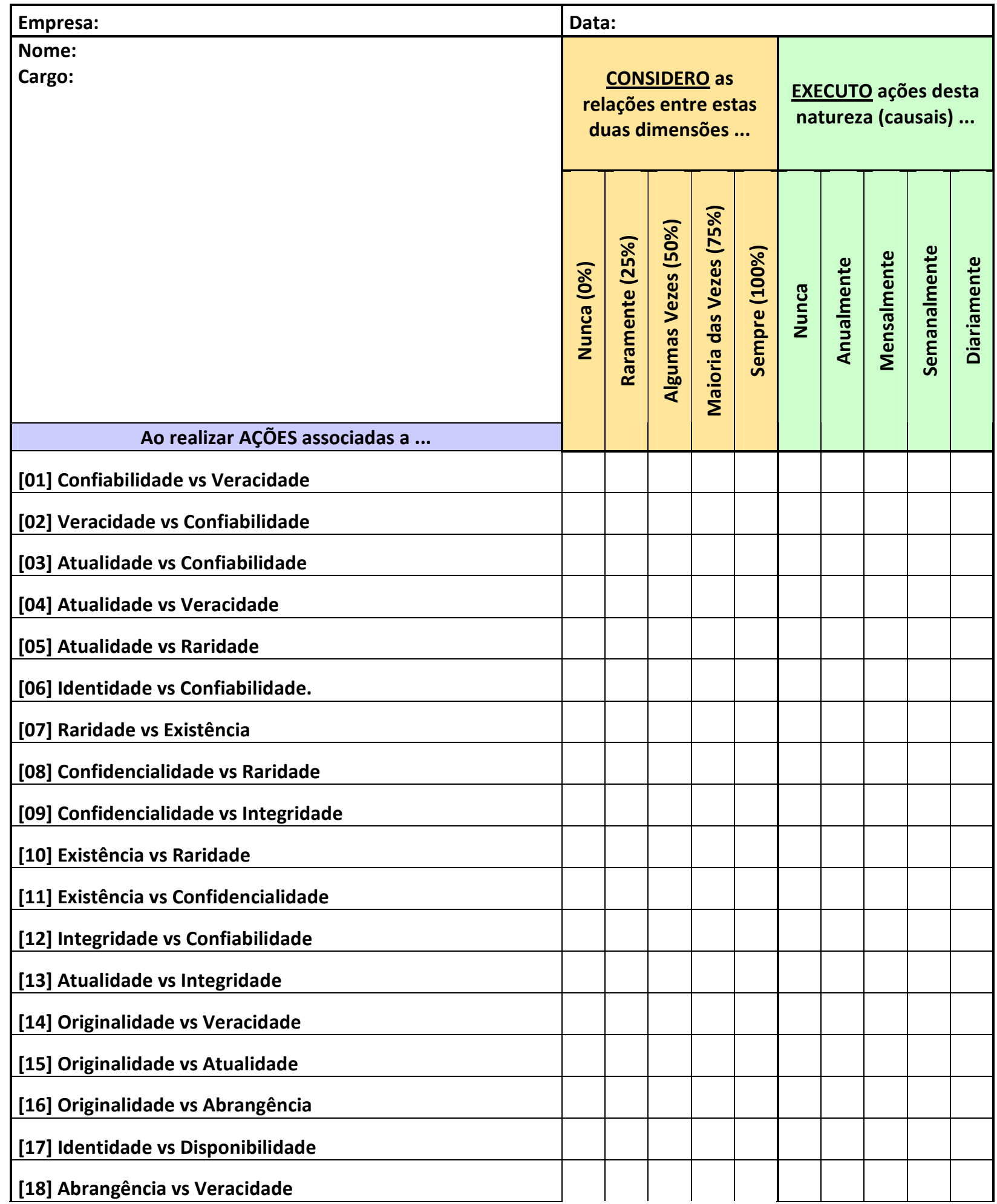




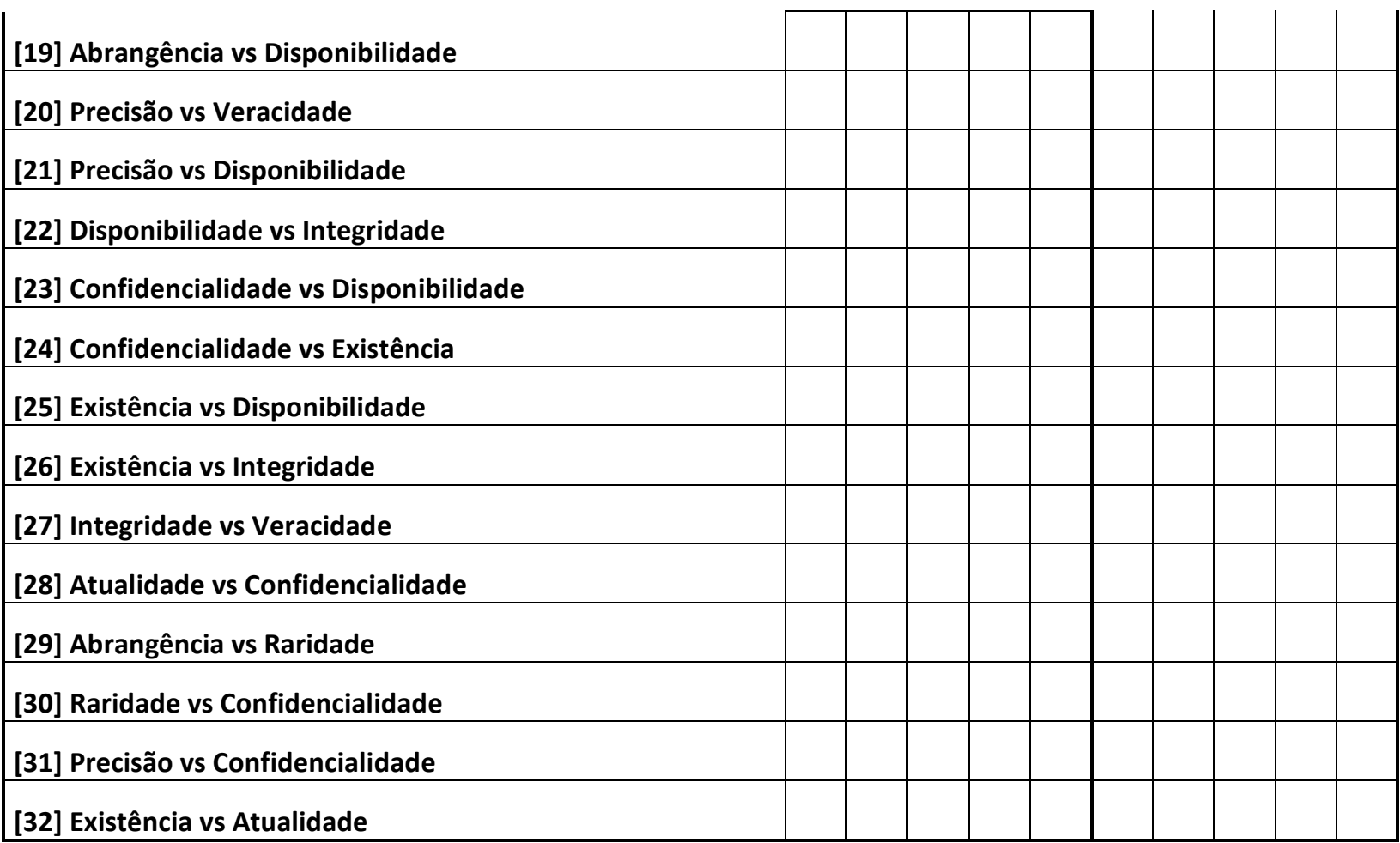




\section{Apêndice B - Instrumento para coleta de dados referente ao comportamentoinformacionaldosfuncionários}

\begin{tabular}{|l|l|l|l|}
\hline Empresa: & Data: & & \\
\hline Nome: & & & \\
\hline Função: & & & \\
\hline
\end{tabular}

Após encontro ocorrido há aproximadamente 45 dias atrás, em que se verificou os conflitos existentes entre as dimensões de qualidade da informação, indique quais as mudanças ocorreram em seu comportamento, considerando a seguinte LEGENDA:
( -2 ) Diminuiu Muito
( -1) Dimuiu Pouco
( 0 ) Manteve
(1) Aumentou Pouco
( 2 ) Aumentou Muito

Em seguida, de um exemplo de seu dia a dia no trabalho que ilustre a mudança ocorrida, por fim, apresente sua justificativa para mudança ocorrida. Há uma linha em branco para cada dimensão caso queira destacar uma outra ação/comportamento.

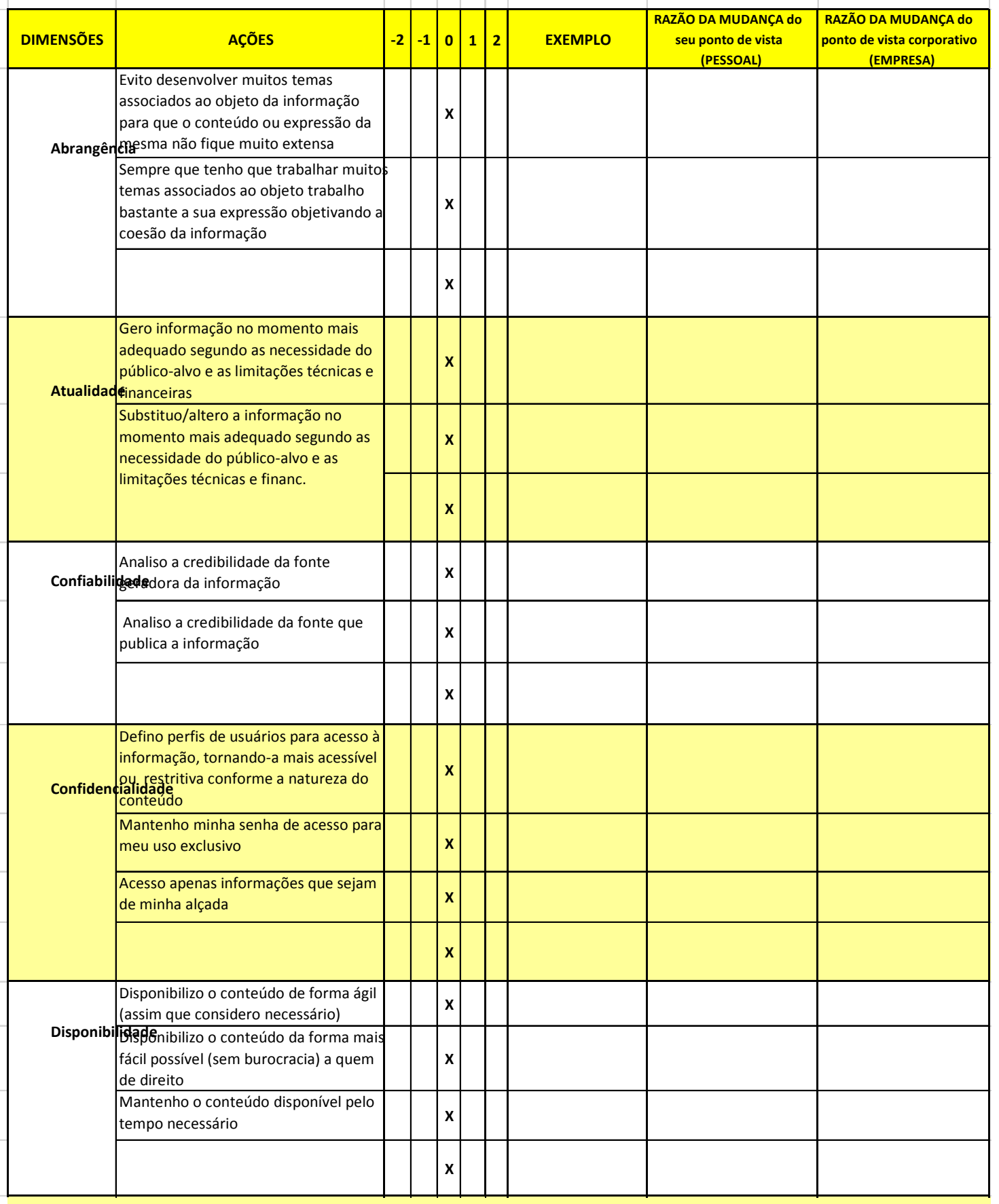


Comportamento informacional: proposição de artefato para reflexão de interdependências entre dimensões de qualidade da informação
José Osvaldo De Sordi;

Thiago Carandina

\begin{tabular}{|l|l|l|l|}
\hline Empresa: & Data: & & \\
\hline Nome: & & & \\
\hline Função: & & & \\
\hline
\end{tabular}

Após encontro ocorrido há aproximadamente 45 dias atrás, em que se verificou os conflitos existentes entre as dimensões de qualidade da

informação, indique quais as mudanças ocorreram em seu comportamento, considerando a seguinte LEGENDA:
(-2) Diminuiu Muito
(-1) Dimuiu Pouco
( 0 ) Manteve
(1) Aumentou Pouco
( 2 ) Aumentou Muito

Em seguida, de um exemplo de seu dia a dia no trabalho que ilustre a mudança ocorrida, por fim, apresente sua justificativa para mudança ocorrida. Há uma linha em branco para cada dimensão caso queira destacar uma outra ação/comportamento.

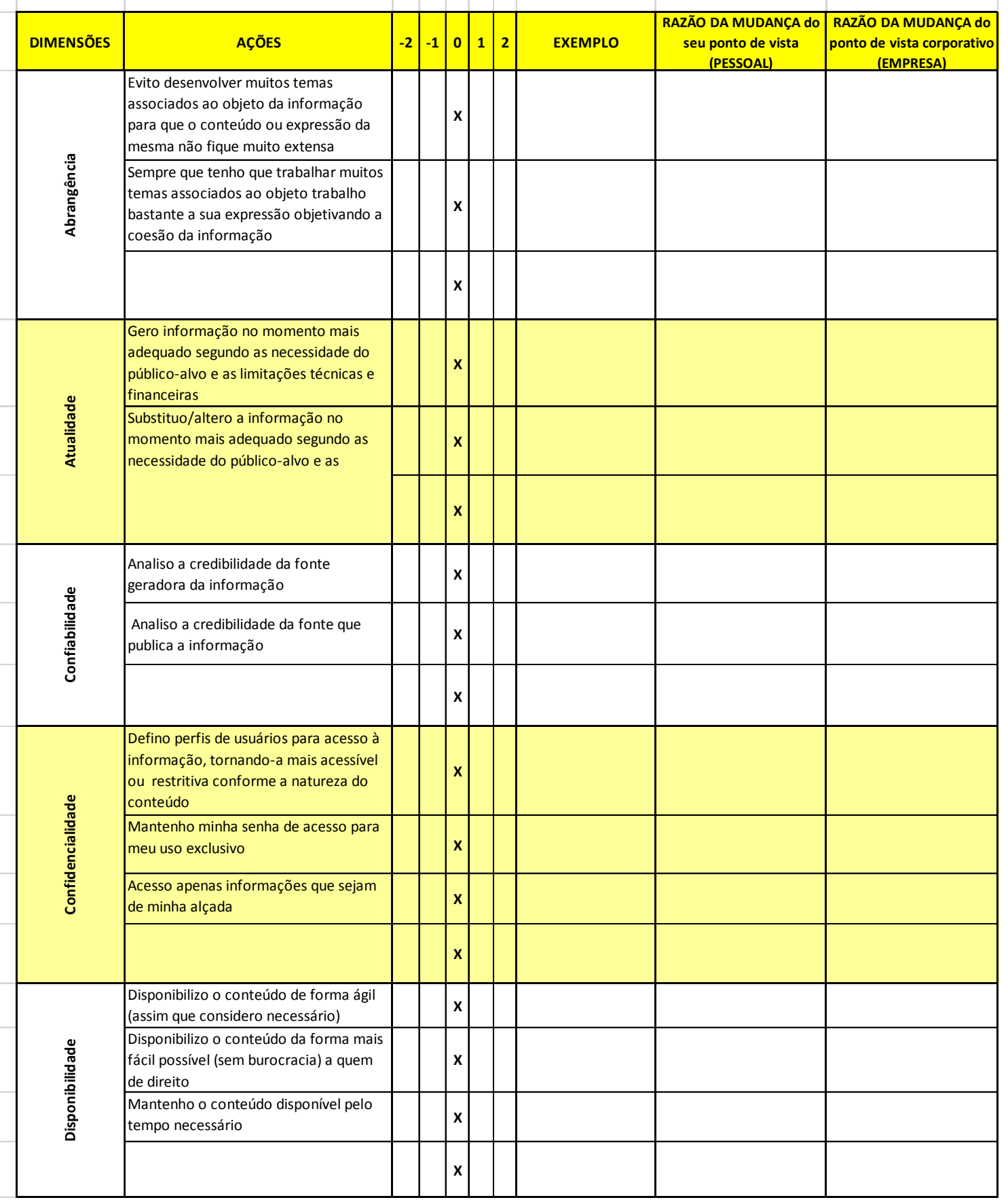


Comportamento informacional: proposição de artefato para reflexão de interdependências entre dimensões de qualidade da informação

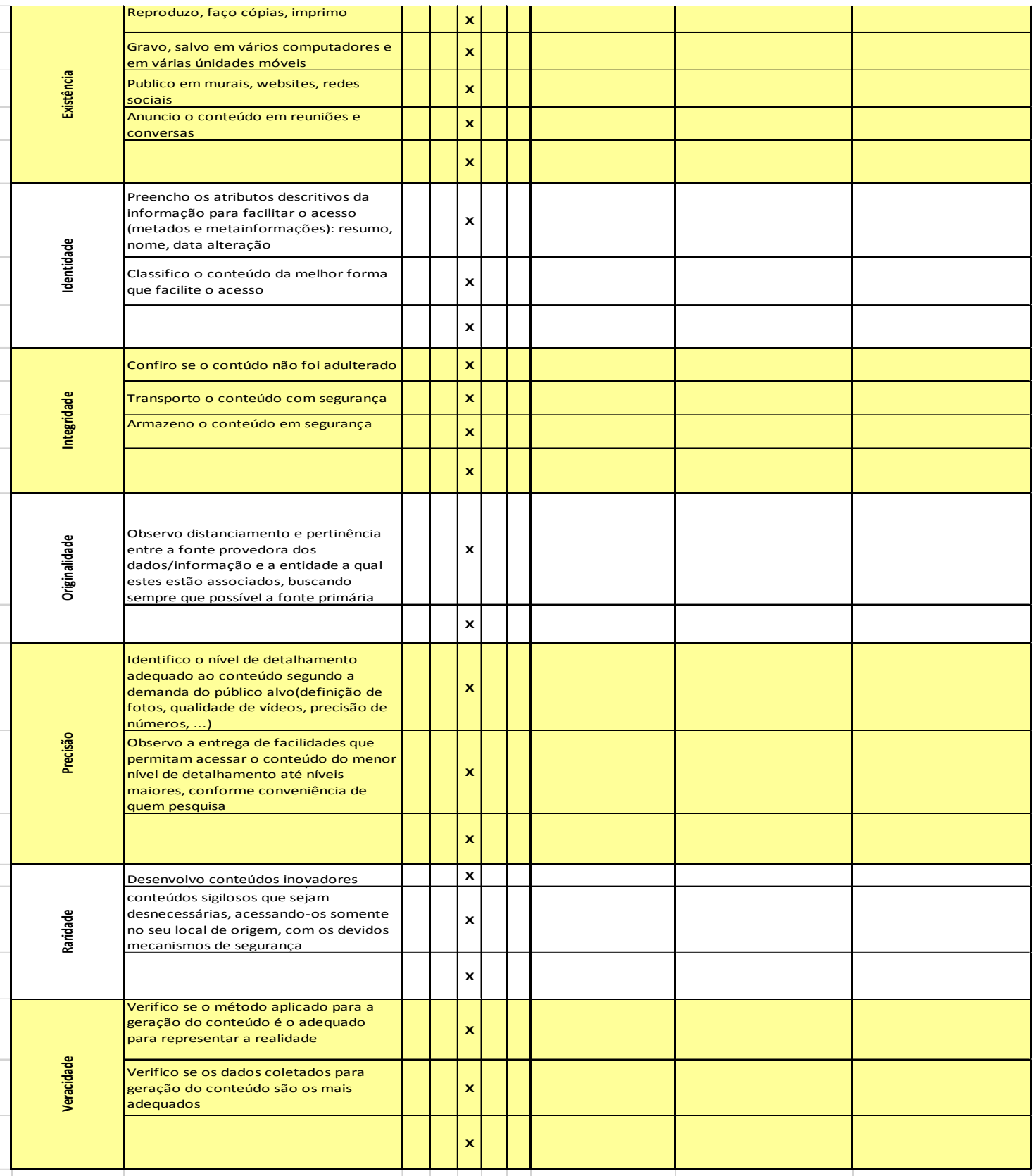

